\title{
Medievalista
}

\section{Os leitores do Espelho de Cristina: um recorte das} cortes

The readers of Espelho de Cristina: a clip of the courts

\section{Ana Luisa Sonsino}

\section{(2) OpenEdition}

\section{Journals}

\section{Edição electrónica}

URL: http://journals.openedition.org/medievalista/1739

DOI: 10.4000/medievalista.1739

ISSN: 1646-740X

\section{Editora}

Instituto de Estudos Medievais - FCSH-UNL

\section{Refêrencia eletrónica}

Ana Luisa Sonsino, "Os leitores do Espelho de Cristina: um recorte das cortes », Medievalista [Online], 25 | 2019, posto online no dia 17 março 2019, consultado no dia 01 maio 2019. URL : http:// journals.openedition.org/medievalista/1739; DOI : 10.4000/medievalista.1739

Este documento foi criado de forma automática no dia 1 Maio 2019

(C) IEM 


\title{
Os leitores do Espelho de Cristina: um recorte das cortes
}

The readers of Espelho de Cristina: a clip of the courts

\author{
Ana Luisa Sonsino
}

\section{NOTA DO EDITOR}

Data recepção do artigo / Received for publication: 31-05-2018

Data aceitação do artigo / Accepted in revised form: 07-12-2018

\section{NOTA DO AUTOR}

Bolseira FCT desde 2017 - SFRH/BD/131612/2017

\section{Introdução}

1 O que pode levar um filólogo a aventurar-se no estudo da vida quotidiana nas cortes medievais? Élida Lois afirma que "[l]a materialidad y la operatoria de la escritura están atravesadas de historicidad y nunca podrán ser auténticamente interpretadas sin dar cuenta de esa condición"1. Segundo esta autora, embora não se possa dizer que a génese de um texto seja "una función mecánica de procesos históricos o de condicionamientos ideológicos (...) tampoco puede dejar de señalarse la existencia de campos de interacción entre lo literario y lo social (...)"2. Por outro lado, é aceitável considerar que, da mesma maneira que a génese de um texto está intimamente relacionada com diversos factores sócio-históricos, também o estarão as traduções que dele se façam. Com efeito, Tobias Brandenberger assegura que, se nos focássemos nos

tiempos en los que la asequibilidad de libros fuera de las zonas de su difusión

original estaba aún sumamente condicionada por el simple hecho de que fueran 
traducidos y circularan de ese modo en territorios alófonos, se nos plantearían diversas preguntas relacionadas, a la vez, con los receptores (...) y con las condiciones (...) de la traducción ${ }^{3}$. iniciativa da rainha, entrariam em contacto com o texto do agora chamado Espelho de Cristina, passado pouco mais de um século de ele ter sido redigido? Talvez a resposta a esta pergunta se possa alinhar ao estudarmos e compararmos alguns aspectos da França que viu nascer a obra, com o Portugal em que aparece a sua primeira edição impressa em português.

4 Ao longo da intensa pesquisa bibliográfica realizada tornou-se evidente, sem grande surpresa, que vários autores tinham já reflectido sobre e interrogado a tradução (traduções? ${ }^{5}$ ) desta obra de Christine de Pisan: Tobias Brandenberger, em 2001, questionou-a acerca do público a que estaria dirigida, e ainda sobre a possibilidade de este mesmo público ter estado na origem das alterações que o texto-base sofrera ao ser vertido para português, na altura da sua impressão ${ }^{6}$. Anteriormente, em 1999, Ivone Leal reflectiu acerca da importância que a obra poderia ter no início do século XXI, quando o original tinha sido escrito em França em inícios do século XV, para as mulheres de então ${ }^{7}$. Ambos os autores encontraram respostas para as suas interrogações quer no texto de Christine, quer na análise sócio-histórica do espaço / tempo da produção do original e das versões portuguesas. Tal permite supor que o caminho escolhido para encontrar a resposta à pergunta antes formulada parece poder conduzir-nos a ela. Comecemos então a percorrêlo.

\section{0 texto (original) em contexto:}

\section{Christine, a França da sua época e o seu público leitor}

Para poder dar um contexto acabado à produção escrita de Christine de Pisan em geral, e ao Livro das Tres Vertudes (1405) em particular, não se pode senão começar com um relato biográfico, ainda que sucinto. Isto porque se o percurso de vida de um autor influencia sempre a sua obra, no caso da nossa autora tal não acontece de forma inconsciente, nem tenta evitar-se. Muito comprometida com a sua época, Christine não apenas impregnava a sua obra com as suas emoções, ideologias e ideais, mas, ainda, relatava nela experiências vividas na primeira pessoa ${ }^{8}$. Contudo, o surgimento de um texto e a sua transmissão não dependem apenas das vivências do autor mas, ainda, do contexto histórico em que nasce e do seu público (tanto aquele a que estava destinado, como aquele que efectivamente irá lê-lo). Assim sendo, apresentarei um resumo que, não pretendendo ser exaustivo, permite assinalar alguns traços deste público e das suas circunstâncias. 


\section{Christine}

6 Nascida em Veneza, em 1364, filha de Tommaso da Pizzano e da filha do anatomista Tommaso de Mondino', teria entre três e quatro anos quando, com a família, se mudou para Paris, onde o seu pai morava havia já algum tempo ${ }^{10}$. Médico e astrólogo, Thomas de Pisan (como passou a ser conhecido) fora físico e conselheiro científico do rei Carlos V, que o tinha em alta estima. Christine cresceu desde então no ambiente da corte parisina, pois "el rey mandó que la hija de su físico participara en todas las fiestas y divertimientos de la corte compatibles con su tierna edad y fuera educada como una princesa"11. Assim, pôde frequentar a magnífica biblioteca régia que acabara de ser instalada no palácio do Louvre, além de receber do próprio pai - a figura de maior peso na vida de Christine nesta área - uma educação invulgar para uma mulher da época. De facto, foi o pai quem insistiu para que a filha fosse instruída em francês, latim e italiano, enquanto a sua mãe se opunha a que recebesse formação, preferindo que aprendesse a fiar, costurar e bordar entre outros afazeres próprios das mulheres da sua condição, o que levou a que não aprofundasse os seus estudos tanto quanto teria gostado.

7 Aos quinze anos casou com Étienne du Castel, um nobre - notário de profissão - nove anos mais velho, que acabara de ser nomeado secretário do rei. Étienne, sendo ele próprio um intelectual, incentivou Christine a prosseguir a instrução. Tiveram um casamento feliz que se prolongou por dez anos, ao longo dos quais nasceram três filhos, uma menina e dois meninos, tendo o mais novo morrido ainda pequeno.

8 A sorte de Christine começaria, contudo, a mudar, e não para melhor, no próprio ano em que casou. Com efeito, nessa altura morreu a rainha Joana de Bourbon, algum tempo depois o condestável Bertrand du Guesclin e, por último, o próprio rei Carlos V, em Setembro de 1380, evento que se converteu numa baliza temporal de grande importância na vida da família de Christine (e não só). A partir da morte do rei, a posição de Thomas de Pisan na corte mudou radicalmente: tanto ele como a sua obra foram questionados, perdendo prestígio, o ordenado foi primeiro reduzido e depois pago irregularmente, o que fez com que, na altura da sua morte (em finais de 1387), estivesse seriamente endividado. Não obstante, Christine e a sua família puderam continuar a manter um certo nível de vida graças ao cargo de secretário real do seu marido. Porém, a grande alteração dá-se quando, no outono de 1389, enquanto se encontrava a acompanhar o rei Carlos VI numa missão oficial, Étienne morre de peste em Beauvais.

Mãe viúva, sozinha com três filhos e uma sobrinha que lhe deixara um dos seus dois irmãos para que a casasse (ambos voltaram para Itália, depois da desgraça se abater sobre a família, para tratar de assuntos ligados à sucessão, acabando por não mais regressar a França), Christine assume o encargo de toda a administração familiar, tarefa que tinha sido sempre desempenhada pelos defuntos pai e marido. Nessa condição, apercebeu-se de que o rei devia ao seu marido não apenas os honorários habituais, mas também outros pagamentos em atraso; que o departamento financeiro real não lhe reconhecia a propriedade sobre um bem adquirido pelo marido pouco antes da sua morte; que fora enganada por um comerciante que lhe roubou o dote dos filhos. Assim se inicia um período que se veio a verificar um verdadeiro "calvário legal", marcado pelo sacrifício, pela humilhação e pelos pleitos, nos quais nunca seria bem representada e em que acabaria por perder, em termos económicos, mais do que, graças a eles, recuperara. 
10 É, portanto, no meio da dor pela perda do pai e do marido e pela aflição económica a que foi submetida em virtude das injustiças legais que, com frequência, acometiam as viúvas naquela época, que Christine começa o processo que ela própria identificaria como sendo de metamorfose. Dá-se uma profunda mudança interior que viria a descrever como a sua transformação "em homem", pelas características de personalidade e comportamento que teve de adquirir, ou seja, passou de uma posição de fragilidade extrema enquanto viúva muito nova, para a de solidez de uma mulher capaz de sustentar a sua mãe, os dois filhos que sobreviveram e a sua sobrinha.

11 É ao longo desta década conturbada, após recuperar alguma riqueza com a venda de uma das propriedades herdadas do pai e superar uma doença prolongada, que Christine começa a escrever. Primeiro, fê-lo para aplacar a perda do marido e, por volta de 1399 (ano em que ela própria situa o início do seu percurso como escritora profissional), reconhecendo na actividade outra dimensão, começa a procurar mecenas para poder fazer da escrita a sua profissão, abrangendo na sua obra um leque de temáticas e géneros muito mais vasto e complexo do que as baladas de amor com que começara anos atrás. Trabalhou ainda como copista de manuscritos (o que lhe teria permitido, além de ganhar dinheiro, aumentar a própria biblioteca) e, ao que parece, chegou a ter uma pequena oficina para desenvolver esta actividade junto dos seus colaboradores.

12 Quanto às crianças que ficaram sob sua custódia, Marie, a sua filha, entrou na abadia de Poissy em 1397, enquanto Jean, o filho supérstite, foi enviado para a Inglaterra, em 1399, para ser educado na corte de Ricardo II, sob a tutela do conde de Salisbury e, mais tarde, ficou ao serviço do duque de Borgonha, Filipe o Audaz. Em 1406, Christine conseguiu ainda que o duque de Borgonha, João sem Medo, oferecesse o dote para que a sua sobrinha pudesse casar.

13 A fortuna de Christine mudaria outra vez por volta de 1400, altura em que produziu as primeiras obras que a tornariam famosa e conhecida para além das cortes francesas. Já em 1399, com o seu poema "Epitre au dieu d'Amour", começou a mostrar a sua preocupação com a imagem da mulher que estava a tornar-se aceite na sociedade francesa. A sua posição ficará completamente consolidada não muito depois, no seguimento da sua intervenção na querela do Romance da Rosa, ao que parece o primeiro debate literário francês de que há notícia ${ }^{12}$. 0 Romance, escrito inicialmente por Guillaume de Lorris, c. 1236, consistia num poema de amor cortês que grangeou enorme êxito na Europa da época, apesar de ter ficado inacabado. Meio século mais tarde, a escrita do poema é retomada por Jean de Meun, que, deitando mão a uma sátira misógina, subverte o sentido original da obra, transformando-a num arrazoado hostil ao amor, ao matrimónio e a tudo o que estivesse relacionado com "a mulher". Em 1401, Jean de Montreuil, secretário de estado e preboste de Lille, compôs um breve tratado elogiando o acrescento de Jean de Meun, difundindo ambos pelos círculos literários parisinos. Foi em resposta a este tratado que Christine redigiu a primeira das várias cartas que viria a escrever a propósito desta questão, que se prolongará até Jean Gerson, chanceler da Universidade de Paris, encerrar a disputa em 1402. Apesar das agressões e da desqualificação de que foi objecto durante esse período, Christine teve nesta querela literária a possibilidade de ser conhecida por um público mais alargado e aumentar os seus contactos com outros intelectuais. Iniciou, assim, a sua batalha literária em defesa da mulher, em torno da qual centraria uma parte importante da sua obra, que termina com Le ditié a Jehanne d'Arc, em 1429. Entre Dezembro de 1404 e Abril de 1405 escreveu o Livre de la cité des dames, uma ginecotopia que é, a um tempo, uma genealogia das mulheres e 
um discurso em sua defesa. Logo a seguir, entre a primavera e o mês de Novembro do mesmo ano ${ }^{13}$, compôs a primeira obra didáctica para o público feminino escrita por uma mulher, o Livre des trois vertus, que imaginou multiplicada e difundida pelo mundo fora, alcançando as mulheres de todas as condições sociais ${ }^{14}$. Este segundo livro era uma espécie de guia a seguir para que qualquer mulher pudesse aceder à "Cidade das Damas", a cidadela onde a misoginia imperante na época não as poderia atingir, nem magoar.

Em 1416, a sorte mudaria novamente, mas desta vez não apenas para Christine: toda a França se viu envolvida numa crise política e social. Os distúrbios sangrentos e numerosos, dado o risco que representavam, levaram a que a família de Christine saísse de Paris. Por volta de 1418, Jean, seu filho, partiu para o exílio acompanhado da mulher e de três filhos pequenos; Christine reuniu-se com a filha em Poissy, onde acabaria os seus dias cerca de $1430^{15}$.

\section{França}

15 Christine dá início ao seu percurso como escritora numa das fases mais turbulentas da história de França, ou seja, tendo a Guerra dos Cem Anos como pano de fundo. Depois da morte de Carlos $\mathrm{V}$ assiste-se a um período de grande instabilidade política, uma vez que se dá início a uma luta pelo poder entre os tios do "Delfim", em lugar de respeitar a sua vontade. Assim, enquanto o duque de Anjou se apropriava do tesouro real, os restantes tios procuravam apoderar-se da maior quantidade de território possível. Apesar de Carlos VI ter sido coroado ainda muito novo na tentativa de refrear o crescendo de conflitos internos, a situação tenderia a agravar-se. As turbulentas relações de poder entre Luís de Orleãns, por um lado, e Isabel de Baviera e o seu filho, por outro, não ajudavam a acalmar a situação, e a morte de Filipe "O Atrevido" só veio agudizar a luta entre os príncipes. Contudo, estas disputas entre casas reais não apenas não afectaram a capacidade de Christine em encontrar mecenas em praticamente todas as suas cortes - com uma habilidade pouco comum -, como ainda a motivaram e inspiraram para escrever obras que tratam da reconstrução moral do país através da difusão do saber, chegando a debater quem o devia reger ${ }^{16}$.

16 A querela do Romance da Rosa surge precisamente no momento "en que algunos se dedicaban a inventar la costumbre francesa y otros a falsificar la ley sálica con el objetivo de legitimar la exclusión de las mujeres del trono real" ${ }^{17}$. Segundo Sarah Hanley, Christine de Pisan apercebeu-se das consequências a nível moral e político que a difamação das mulheres traria consigo e, por isso, teria iniciado o debate. Posteriormente, no Livre de la Cité des Dames, a autora arrolou uma espécie de "censo de todas las mujeres que habían reinado a lo largo del tiempo y a lo ancho del mundo y demostraba, además, la legitimidad de esos reinados"18, a fim de neutralizar ou, pelo menos, aplacar os resultados do pérfido trabalho de equipa levado a cabo por alguns "guardiães" da moral e da política. Com efeito, os primeiros encarregavam-se de difamar as mulheres para que aos segundos lhes fosse mais fácil conseguir a sua exclusão do governo; foi este o mecanismo que Christine ousou desafiar publicamente.

17 As lutas pelo poder e os distúrbios políticos e sociais alcançariam o seu auge após a queda de Agincourt e a morte de Luís de Guyenne. As intrigas e traições aumentaram até ao cruento ataque dos Borguinhões aos Armagnacs em 1518, dando clara vantagem aos ingleses. Desde então e até 1429 , houve fases de sucessos e de falhanços em ambos os lados, tal como períodos de triunfos ingleses, até ao cerco a Orleães. A resistência e 
posterior libertação desta cidade foi o princípio do fim da ocupação inglesa. A 17 de julho de 1429, Carlos VII foi coroado em Reims ${ }^{19}$ e, no último dia do mesmo mês, Christine de Pisan terminou, aos quase sessenta e cinco anos, a redacção do poema em louvor de Joana d'Arc ${ }^{20}$, sua última obra.

\section{O público} assentarem, nas palavras de João Gouveia Monteiro, na cabeça de dois reis adolescentes e, portanto, muito influenciáveis -, ambos os reinos viveriam durante anos numa constante instabilidade interna, levando a um prolongado período de tréguas na Guerra dos Cem Anos $^{21}$. Desde então e até à derrota de Agincourt, contrariamente ao que se poderia pensar, o patrocínio das artes em França aumentou exponencialmente. Com efeito, por causa das rivalidades políticas existentes, "[1]as cortes potenciaron el patronazgo de las artes ya que por un lado servían de animación en la vida de la corte y, por otro, la influencia de la corte de cara al exterior se veía nutrida de prestigiosos personajes" ${ }^{\prime 2}$. Apesar de Christine ter aproveitado com grande habilidade esta conjuntura e de as suas obras terem sido amplamente apreciadas neste âmbito, a verdade é que a circulação dos seus livros, em particular do Livre des trois vertus, não se cingiu apenas às cortes francesas.

Vejamos, pois, pela mão de C. C. Willard ${ }^{23}$, como a tradição dos exemplares manuscritos da obra de Christine, e em particular do Livre des trois vertus, ajuda a compreender quem seria o seu público leitor. Com base em dados obtidos por investigadores de várias áreas ligadas ao estudo de manuscritos, a autora avança com algumas propostas sobre quem possuía e, portanto, presumivelmente lia os livros de Christine de Pisan. C. C. Willard distribui os manuscritos em vários grupos em função de diferentes momentos de popularidade. 0 primeiro é o grupo dos manuscritos produzidos em Paris ainda em vida da autora: são edições de luxo, em pergaminho e ricamente decorados, cujos destinatários seriam os bibliófilos da corte. O segundo compreende os manuscritos copiados na corte de Borgonha em meados do século XV. E o terceiro, os pertencentes à corte francesa do último quartel do mesmo século. Embora C. C. Willard não o diga explicitamente, depreende-se da sua análise que estes teriam características similares aos do primeiro grupo. $O$ mesmo não aconteceria com um quarto grupo para o qual a autora chama a nossa atenção e que, embora não sendo por ela datado, parece ser posterior aos mencionados anteriormente (ou parcialmente coincidente com o último): o dos manuscritos em papel. De pouco valor artístico e de duvidosa, se não nula, utilidade para estabelecer o texto-base de uma edição, este grupo caracteriza-se pela numerosa quantidade conservada, facto que revela o interesse que a obra de Christine, e em particular a sua prosa, suscitava na "classe média" da época.

Contudo, no que diz respeito ao Livre des trois vertus, Willard diz que "[i]t is surprising to discover (...) that the manuscript tradition for this particular text does not quite conform to the general pattern"24. Segundo a autora, apesar de ser possível identificar dezoito manuscritos que contêm este texto, só um deles pertence ao primeiro grupo acima referido (datado de c. 1405). Existem ainda dois ou três que, pelas suas iluminuras, podem ser considerados como inspirados nas primeiras cópias, mas de qualidade inferior (datados do segundo quartel do século XV). A configuração destes manuscritos - que, curiosamente, parecem ter sido produzidos em locais vinculados às irmãs de Margarida 
de Borgonha - sugere que pertenceram a leitores de uma "classe média em ascensão". Das várias cópias realizadas no terceiro quartel do século XV (e, portanto, parte do terceiro grupo), interessa aqui destacar a que parece ter pertencido ao maitre d'hôtel de Isabel de Borgonha, e uma outra, um códice de Viena - cidade onde D. Leonor, sobrinha da duquesa de Borgonha e mulher de Frederico III, morava desde 1452. Também a este período pertencem dois manuscritos vinculados à corte francesa, uma vez que surgem listados num inventário de cerca de 1500 da biblioteca dos Bourbons em Moulins. Existe ainda um manuscrito de origem incerta, com armas bretãs no seu primeiro fólio, e nove manuscritos em papel ${ }^{25}$. Tanto estes como as edições impressas da primeira metade do século XVI (três francesas e a portuguesa de 1518) dão conta não apenas da popularidade da obra, mas também da sua difusão fora dos círculos aristocráticos, indo ao encontro do proposto por Cedric Pickford que, em 1963, falava num alargamento do público leitor (embora para o género de ficção) aos sectores burgueses e a outros habitantes da cidade que tivessem recebido educação - mulheres incluídas - no decorrer do século $\mathrm{XV}^{26}$. Esta particular tradição textual do Livre des trois vertus, que pode resultar anómala se observada fora de contexto, é, no entanto, absolutamente coerente quando observamos tanto o conteúdo, como a princesa para quem foi redigida a obra. Com efeito, tendo sido dedicada a Margarida de Borgonha, é natural que tenha suscitado particular interesse primeiro no seio da corte borguinhona e, mais tarde, na corte francesa. Para mais, o tratar-se de um livro que visa educar princesas, mas cujos ensinamentos ambicionam alcançar todas as mulheres (ao longo das três partes que a compõem o leque de mulheres visadas é alargado, ainda que com limitações), compreende-se que tenha cativado leitores alheios ao ambiente cortesão. Igualmente previsível e coerente é o facto de a tradição manuscrita da restante obra de Christine não ter tido o mesmo percurso: os géneros e as temáticas abordadas não foram sempre as mesmas e o seu conteúdo nunca esteve destinado a um público tão alargado quanto o deste texto em particular.

\section{0 texto (traduzido) em contexto}

\section{As mulheres de Avis, a tradução (traduções?) do Livre des trois vertus e o seu público}

Como indicado supra, o Livro das Tres Vertudes vai além da educação de princesas. Nele, Christine de Pisan, guiada pela "Razão, Direitura e Justiça", irá "explicar a las mujeres de todas las condiciones el comportamiento que han de seguir en el diario vivir"27, de modo a poderem habitar mais tarde na Cidade das Damas. É, nas palavras de Ivone Leal, "um livro pedagógico sobre comportamentos sociais em que se podem distinguir dois níveis inseparáveis: os bons costumes e as boas maneiras" ${ }^{28}$, destinado às mulheres de todas as condições sociais e, consequentemente, das mais diversas regiões geográficas. Segundo a mesma autora, um dos motivos que confere particular importância a esta obra no seio da história da cultura portuguesa é o facto de se desconhecerem (o que não quer dizer que não tenham existido) obras didácticas escritas por ou destinadas a mulheres anteriores ao Livro das Tres Vertudes, tornando-o assim no primeiro livro de educação deste tipo posto à disposição do "público feminino português" ${ }^{29}$. $\mathrm{O}$ facto de ter sido sucessivamente traduzido e impresso por ordem real, bem como a notícia - que surge num inventário da casa de Saboia feito em $1538^{30}$ - da existência de uma versão em castelhano da propriedade de D. Beatriz de Portugal, e os sinais que da sua leitura existem na obra de Luisa Sigeas ${ }^{31}$, dão 
conta não apenas da sua permanência na corte portuguesa ao longo dos anos, mas também da sua efectiva utilização. Interessa agora tratar sumariamente a educação das 'meninas' portuguesas dos séculos XV e XVI.

\section{A educação das mulheres da dinastia de Avis}

Segundo a historiadora Manuela Mendonça, é "ao longo do século XV que descortinamos na corte portuguesa a preocupação de criar e viver um ambiente cultural que vem já carregado dos valores das novas correntes humanistas" ${ }^{32}$. Da cultura dos príncipes de Avis dão prova obras como $O$ Leal Conselheiro, a Virtuosa Bemfeitoria, as obras redigidas pelo condestável D. Pedro ou a importante biblioteca compilada por Afonso V. O seu interesse em que os filhos fossem, também eles, cultos, é espelhado no cuidado com que foram educados, convocando para o efeito mestres portugueses e estrangeiros. Mas, provavelmente, a maior inovação que a Casa de Avis concretizou em matéria de educação foi o permitir que tanto homens como mulheres (príncipes e nobres) tivessem acesso a formação. Tal conduziu a que todas as princesas da Casa de Avis deste século fossem tão cultas e instruídas quanto os seus pares masculinos. Este fenómeno, ou outros similares, verificaram-se em diversas cortes europeias, designadamente as da vizinha Castela ou da Borgonha.

É nesta altura que surge em Paris, dirigido a uma princesa borguinhona, o Livre des Trois Vertus, sendo possível que o mesmo tenha circulado também por Portugal no mesmo período, embora não haja dados precisos. Contudo, quer tenha chegado na altura em que Christine de Pisa o escreveu, quer mais tarde, em 1428, com D. Pedro ou, ainda depois, através de D. Isabel aquando do seu casamento com o duque de Borgonha em 1430, é um facto que o Espelho de Cristina foi lido pelas princesas da Casa de Avis. Alem disso, os seus ensinamentos foram levados à prática durante gerações, a começar pela própria duquesa Isabel. Com efeito, e apesar de não se ter a certeza do uso da obra de Christine como manual de formação, a duquesa Isabel actuou sempre segundo os seus preceitos, quer ao exercer as suas funções no âmbito do seu casamento e das relações com a família do seu marido, quer ainda na gestão da relação com a sua família de origem ${ }^{33}$. Quanto às suas sobrinhas, parece ser possível afirmar com mais segurança que foram efectivamente educadas sob a orientação do Livre des Trois Vertus, uma vez que

nas respectivas actuações encontramos marcas destas orientações, não apenas na formação moral e religiosa, mas também no próprio culto do saber, na organização das casas, enfim, nas actuações protocolares e políticas. E, mais que tudo isso, no exercício do modelo de Mulheres íntegras, mas de conduta pautada pelo assumir de uma dignidade própria, forjada numa correcta atitude moral e sedimentada num notável desenvolvimento cultural e intelectual ${ }^{34}$.

Todavia, ter recebido a instrução acima referida "não significa que da formação de infantas, princesas e 'nobles dueñas' estivessem ausentes aqueles que eram, por tradição e 'natureza', os saberes próprios da mulher honesta e virtuosa, ainda que fosse filha de reis e de rainhas ${ }^{35}$ ", ou seja, elas deveriam ainda saber tecer, bordar, organizar a casa, cuidar dos filhos e, obviamente, cultivar a sua devoção cristã diariamente, através da prática e das leituras das obras a isso destinadas ${ }^{36}$. 


\section{A tradução (traduções?)}

C. C. Willard identifica, segundo Rivera-Garretas, no livro Christine de Pizan. Her Life and Works, quatro períodos de popularidade da obra de Christine: o primeiro ainda em vida da autora; o segundo em meados do século XV na corte dos duques de Borgonha; o terceiro em Paris entre a segunda metade do século XV e a primeira do século XVI, e o quarto desde 1883, quando foi novamente descoberta ${ }^{37}$. Destes quatro períodos, interessam-nos particularmente o segundo e o terceiro. Porquê? Sabemos que Le livre des Trois Vertus foi mandado traduzir para português algures entre 1428 (ano do retorno a Portugal, após longa viagem, de D. Pedro, duque de Coimbra) e 1455 (ano do falecimento da rainha D. Isabel de Coimbra, sua filha) ${ }^{38}$. Isto é, justamente em meados do século XV. A ligação entre Portugal e a corte dos duques de Borgonha era, na altura, muito estreita, pois D. Isabel de Borgonha, casada com o duque Filipe "O Bom" em 1430, manteve sempre um vínculo muito forte com a família que deixara na Península, sobretudo depois dos trágicos acontecimentos que tiveram lugar em Alfarrobeira em $1449^{39}$. Se a isto se juntar o que já foi analisado acerca da história dos manuscritos que ainda se conservam, torna-se plausível que tenha sido a duquesa Isabel de Borgonha a enviar nessa altura à sua sobrinha o livro de Christine, cujos ensinamentos poderiam ser de boa ajuda no momento difícil que a rainha $\mathrm{D}$. Isabel estava a atravessar. Tal não resolve, contudo, as seguintes questões: onde e por ordem de quem terá sido feita a tradução. Com efeito, existem várias respostas possíveis, sendo que se referirão apenas as mais credíveis. Uma delas é que a de que tradução poderia ter sido encomendada pela duquesa, ou para a oferecer à sobrinha, ou na altura da sua chegada à corte de Borgonha para uso pessoal, ou ainda em Portugal e antes de partir para a Borgonha, se se verificasse que uma cópia em francês lhe tivesse sido oferecida pelo seu irmão D. Pedro ${ }^{40}$. Outra possibilidade é que a tradução tenha sido encomendada pela rainha D. Isabel, tal como vem indicado no incipit do manuscrito ${ }^{41}$ conservado na Biblioteca Nacional de España ${ }^{42}$. Contudo, a existência desta indicação não pode ser tomada como decisiva, pois o texto desse manuscrito pode ter tido como fonte uma outra cópia da tradução onde tal indicação não constasse. Uma vez que a duquesa e a rainha partilhavam o nome, não seria descabido supor que um copista, na altura de realizar a cópia da tradução, possa ter decidido alterar o incipit do texto ${ }^{43}$. Tendo todas estas alternativas presentes, podemos propor como intervalo temporal credível para a realização da primeira tradução o período entre 1428 (ano em que D. Pedro retorna a Portugal) e 1455 (ano da morte da rainha D. Isabel).

Sabemos ainda que em 1518 foi impresso O Espelho de Cristina, por ordem da rainha D. Leonor (outro membro da Casa de Avis que viveu segundo o prescrito no livro de Christine). Livro que, segundo alguns autores, é fiel à mesma tradução portuguesa transmitida pelo manuscrito, salvo algumas alterações que teriam origem quer na modernização da língua, quer na correcção de um erro de localização textual (deslocação, no manuscrito, de um trecho do capítulo X da terceira parte para o capítulo XI da mesma parte ${ }^{44}$ ). Todos estes autores referem, no entanto, que, a partir do capítulo $\mathrm{X}$ da segunda parte, os textos diferem significativamente, tornando-se independentes. Como explicação para o afastamento textual, Maria de Lurdes Crispim indica que, detectado o erro de deslocação na terceira parte, a pessoa a quem coube a correcção da tradução tratou de a rever até que, a dada altura, por cansaço, por pressa ou por outra razão que desconhecemos, decidiu realizar uma nova tradução a partir do capítulo X da segunda parte $^{45}$. Já Ivone Leal faz eco do que afirma Dorothee Carstens-Grokenberger no estudo 
com que inicia o seu livro Christine de Pisan, Buch von den Drei Tugenden in portugiesischer Übersetzung (1961) e propõe que o encurtamento desta parte final do impresso possa dever-se ao facto de o editor ter achado o livro demasiado extens ${ }^{46}$. Apesar da evidente discrepância que existe entre as versões portuguesas, nenhum autor fala numa nova tradução como texto-base para a edição impressa de 1518. Porém, Sara Sousa, no artigo "Christine de Pizan em Português", indica o seguinte:

Conhecem-se, hoje, duas traduções portuguesas do Livre des Trois Vertus (...). A primeira, intitulada $O$ Livro das Tres Vertudes, encontra-se no manuscrito 11515 da Biblioteca Nacional de Madrid (...). Da outra, impressa em 1518, e que dá pelo nome 0 Espelho de Cristina, estão recenseados três testemunhos ${ }^{47}(. . .)^{48}$.

Estaremos realmente perante duas traduções diferentes? Se sim, o que é que teria motivado a realização desta segunda tradução? É o que se discutirá de seguida.

\section{O público}

Uma vez que esta investigação se desenvolveu a partir da questão de como poderia o texto de Christine de Pisan interessar às mulheres portuguesas, importa atentar às características deste público. Neste sentido, Ivone Leal destaca a boa recepção que as princesas portuguesas deram ao tratado, tomando-a como

uma manifestação clara das afinidades de sentimento e costumes da corte portuguesa com as cortes francesa e borgonhesa, entre outras. E esta proximidade cultural, mais do que um palpite ou uma hipótese, é um facto relativamente fácil de explicar e até de comprovar ${ }^{49}$.

A autora evoca as cartas que Lopo d'Almeida enviou a D. Afonso $V$ quando chefiou a embaixada que acompanhou a princesa D. Leonor ao encontro do seu marido, o imperador Frederico III. Nelas assinala o contraste entre os costumes requintados da corte portuguesa, idênticos aos das cortes francesa e inglesa, e a rudeza dos usos alemães ${ }^{50}$. Não ignorando que passaram mais de cem anos desde a redação do original francês até à publicação do impresso de 1518, a autora afirma que a vigência do texto deixa “transparecer um certo 'atraso' que nos distancia do movimento cultural que ocorre no centro da Europa, e uma certa 'demora' arcaizante no que toca tanto a modelos sociais e culturais, como a económicos" ${ }^{\text {" }}$. Parece-me oportuno relembrar aqui que Christine de Pisan dividiu a obra em três partes: a primeira delas dirigia-se às princesas e grandes senhoras; a segunda, às mulheres das distintas hierarquias nobiliárias (desde as damas da corte até às senhoras de senhorios rurais mais pequenos); a terceira, ocupava-se das diversas categorias de mulheres das cidades e aldeias, as 'mulheres do povo'. Deste modo, e tal como referido antes, Christine pretendia levar os seus ensinamentos a todas as mulheres para que todas pudessem entrar na Cidade das Damas. No entanto, quando Ivone Leal refere o público que a obra alcançou em Portugal, estão apenas em causa as destinatárias das duas primeiras partes.

No artigo "Una traducción bajomedieval y su público: notas acerca del Espelho de Cristina (Lisboa, 1518)", Tobias Branderberger afirma que houve uma primeira tradução para português, intitulada Livro das tres vertudes, fruto de um intercâmbio entre as cortes de Borgonha e Portugal, cujo texto se cinge com bastante fidelidade ao que teria sido o seu antecedente francês ${ }^{52}$. $O$ texto desta primeira tradução teria servido de base para uma segunda tradução, a do Espelho de Cristina, impressa em Lisboa em 1518. Já o texto desta segunda tradução, ao contrário do da primeira, afasta-se de forma clara do antecedente 
francês da primeira tradução $0^{53}$. Por sua vez, no artigo "Christine de Pizan em Portugal: as traduções do Livre des Trois Vertus", o mesmo autor faz notar que, nesta obra,

nem todos os sectores do 'corpo social' recebem a mesma atenção: a estrutura do tratado reflecte o peso das três camadas sociais que correspondem às três partes do livro. A primeira parte é a mais detalhada, a segunda não chega nem à metade da extensão da primeira, enquanto a terceira é ainda mais breve ${ }^{54}$.

31 Não nos vamos deter no significado que este último apontamento pode ter, mas no facto de se alterar (ou não) na realização da segunda tradução. Com efeito, embora a desproporção entre as três partes do livro sempre tenha existido ${ }^{55}$, esta é acentuada no Espelho de Cristina. Para mais, as alterações que reforçam esta discrepância não se produzem de forma aleatória: a tradução vai-se tornando como que num resumo do texto antecedente a partir do capítulo X da segunda parte, ou seja, a partir do momento em que o livro se dirige às mulheres de "classe média e baixa". o último capítulo traduzido sem omissões, o IX da segunda parte, é o dirigido às baronesas, correspondendo ao primeiro que se ocupa das mulheres que vivem fora da corte ${ }^{56}$. Esta alteração nas proporções não é, de todo, inocente. Com ela, a obra $O$ Espelho de Cristina aproxima-se mais de um 'espelho de princesas' do que do texto em que se baseia.

Tobias Brandenberger afirma, em "Una traducción”, que existe uma interdependência entre a tradução que de um texto se faz e o público para ela desejado, isto é, o público previsto influi na tradução e na sua técnica ${ }^{57}$. Com base nesta (muito lógica) apreciação, podemos concluir que o público-alvo da segunda tradução se afastava do previsto originariamente por Christine, cingindo-o às mulheres da corte ${ }^{58}$. Assim, ao invés do que faria supor a realização de uma edição impressa de um livro destas características, a intenção desta segunda tradução não seria produzir uma "edição popular", mas sim uma versão do livro de Christine mais próxima de outros livros didácticos da época. Todavia, importa perguntar porque faria sentido tal decisão no contexto da corte da rainha D. Leonor, uma figura interessada pelos mais desfavorecidos. Provavelmente, a resposta a esta pergunta poderá ser formulada a partir de outro aspecto fulcral também apontado por Tobias Brandenberger: o contexto em que se insere um texto, designadamente a sua relação com os outros textos ${ }^{59}$. Ao referirmos as circunstâncias da redacção do Livre des Trois Vertus e a mensagem que a obra pretendia transmitir a todas as mulheres, estamos necessariamente a referir o Livre da Cité des Dames. Com efeito, embora pudessem ser lidos em separado, ambos os livros estavam intimamente relacionados, tendo subjacente a ideia de que um seria a "teoria" e o outro a "prática". Neste particular, não nos é possível, no entanto, atentar à tradução portuguesa do Livre da Cité des Dames porque, se a houve na altura, hoje é-nos desconhecida. Ao traduzir apenas o Livre des Trois Vertus, o público feminino português tinha acesso a um livro que se poderia configurar como 'a parte prática' de uma 'teoria' (no caso, uma construção teórica) que desconheciam. o que transformaria o Livro das tres vertudes e o Espelho de Cristina em obras puramente didácticas, sem o pano de fundo teórico-disputativo que o Livre da Cité des Dames e todo o contexto prévio da querela do Romance da Rosa conferia ao Livre des Trois Vertus. Com efeito,

[o] facto de o Livre des trois vertus ter sido traduzido (e, logo, recebido em Portugal), sem a obra que o precedeu e que serve, efectivamente, como pré-texto, tem consequências relevantes. São vários os aspectos particulares do Livre des trois vertus que têm a sua explicação na Cité; [e que] pela transferência isolada ficam sem legitimação ${ }^{60}$. 
Uma vez aceite que a descontextualização da tradução transforma $O$ Espelho de Cristina numa obra puramente didáctica, não resulta difícil compreender, nem tão pouco aceitar, os recortes feitos pelo segundo tradutor. 0 objectivo da obra e o seu público-alvo mudam - embora apenas parcialmente ${ }^{61}-$, porque o contexto, neste caso a ausência do prétexto e do contexto do debate, também se altera.

\section{Conclusões}

O caminho percorrido permitiu estabelecer uma ligação não apenas entre o contexto social, histórico e político na génese e transmissão de uma obra, mas também a relação entre esses mesmos elementos e a elaboração de uma tradução. De facto, embora a vivência nas cortes francesa do século XV e portuguesa do século XVI tenha várias proximidades (e o tipo de intrigas e conflitos entre as famílias da alta nobreza também), o texto traduzido oferecido ao público português em inícios do século XVI difere, e muito, dos textos dos manuscritos franceses, das primeiras edições francesas e, ainda, da primeira tradução portuguesa. Um aspecto que, analisado isoladamente, parece não fazer sentido dada a proximidade cortesã. Contudo, o facto de se tratar de uma tradução e de ter decorrido um século não é irrelevante, pois ao perderem-se elementos que davam contexto ao Livre des Trois Vertus, tais como o Livre da Cité des Dames e toda a produção relacionada com a querela do Romance da Rosa, perderam-se referentes que tornariam claro que o Livre des Trois Vertus não era, nem pretendia ser, um espelho de princesas, ou, pelo menos, não só. Neste sentido, é admissível propor que o afastamento temporal da realização da obra, a par da descontextualização da tradução, pode conduzir ao erro de considerar ou mesmo de tentar transformar o Livre des Trois Vertus num espelho de princesas, assim perdendo dimensões importantes quer do texto, quer do alcance que pretendia obter.

\section{BIBLIOGRAFIA}

Fontes manuscritas

PISAN, Christine de - Livro das tres vertudes a inssinança das damas. Madrid, Biblioteca Nacional de España, Ms. mss/11515.

Fontes impressas

PISAN, Christine - La Ciudad de las Damas. Ed., Tradução e Introdução de Marie-José Lemarchand. $2^{a}$ ed. Madrid: Ediciones Siruela, 2001.

PIZAN, Christine de - O Livro das Tres Vertudes a Insinança das Damas. Ed. e Introdução de Maria de Lourdes Crispim. Lisboa: Editorial Caminho, 2002.

Estudos 
AGOSTINHO, Paulo Jorge; MARTINS, Miguel Gomes; MONTEIRO, João Gouveia - Guerra e Poder na Europa Medieval. Das cruzadas à guerra dos 100 anos. Coimbra: Imprensa da Universidade de Coimbra, 2015.

BRANDENBERGER, Tobias - "Christine de Pizan em Portugal: as traduções do Livre des Trois Vertus”. in EARLE, Tom F. (Ed.) - Actas do Quinto Congresso da Associaçào Internacional de Lusitanistas. Universidade de Oxford: 1 a 8 de Setembro de 1996. Vol. I. Oxford / Coimbra: Associação Internacional de Lusitanistas, 1998, pp. 423-433.

BRANDENBERGER, Tobias - "Una traducción bajomedieval y su público: notas acerca del Espelho de Cristina (Lisboa, 1518)". in MARTÍNEZ ROMERO, Tomàs; RECIO, Roxana (Eds.) - Essays on Medieval Translation in the Iberian Peninsula. Castelló de la Plana: Publicacions de la Universitat Jaume I, 2001, pp. 75-94.

BROWN-GRANT, Rosalind - Christine de Pizan and the moral defence of women. Reading beyond gender. Cambridge: Cambridge University Press, 1999.

BUESCU, Ana Isabel - "Educar o Príncipe no Século XVI". in BUESCU, Ana Isabel - Na corte dos Reis de Portugal. Saberes, ritos e memórias. 2ª Ed. Lisboa: Edições Colibri, 2011, pp. 11-51.

CARRARA, Eliana - "Christine de Pizan. Biografia di una donna di lettere del XV secolo". Quaderni medievali 29 (1990), pp. 65-81.

CORREIA, Licínia Maria da Trindade - A Insinança das Damas. Formas de Poder Feminino no século XV (o caso de Isabel de Lencastre). Lisboa: Universidade Nova de Lisboa, 2013. Dissertação de Mestrado. HANLEY, Sarah - "La ley sálica”. in FAURÉ, Christine (Dir.) - Enciclopedia histórica y política de las mujeres. Europa y América. Trad. Marisa Pérez Colina. Madrid: Akal, 2010, pp. 21-38.

HOMET, Raquel - "Espacios femeninos en la pluma de Christine de Pizan. El Libro de las tres virtudes o Tesoro de la Ciudad de las Damas". Comunicação apresentada no IV Congreso Internacional de Estudios Medievales - VI Encuentro de Estudios Medievales, San Juan, Argentina, 2015. Disponível em

https://www.academia.edu/28949169/

ESPACIOS_FEMENINOS_EN_LA_PLUMA_DE_CHRISTINE_DE_PIZAN

LACARRA LANZ, Eukene - "Las enseñanzas de Le livre des trois vertus à l'enseignement des dames de Christine de Pizan y sus primeras lectoras”. Cultura Neolatina LXI (2001), pp. 335-360.

LEAL, Ivone - Cristina de Pisano e todo o universo de mulheres. Colecção Cadernos da condição feminina 52. Lisboa: Comissão para a igualdade e para os direitos das mulheres, 1999.

LOIS, Élida - "La crítica genética: un marco teórico sobre la disciplina, objetivos y método". Creneida [Em linha] 2 (2014), pp. 57-78 [Consultado a 10 de Julho de 2017]. Disponível em http:// www.creneida.com/revista/creneida-2-2014/la-cr\%C3\%ADtica-gen\%C3\%A9tica-un-marco-te\% C3\%B3rico-sobre-la-disciplina-objetivos-y-m\%C3\%A9todos-\%C3\%A9lida-lois/

MENDONÇA, Manuela - “O Espelho de Cristina (séc. XV)”. História Revista 18, 1 (2013), pp. 53-68.

McCASH, June Hall - “The Cultural Patronage of Medieval Women: An Overview”. in McCASH, June (Ed.) - The Cultural Patronage of Medieval Women. Georgia: The University of Georgia Press, 1996, pp. 1-49.

PICKFORD, Cedric E. - "Fiction and the reading public in the fifteenth Century". Bulletin of the John Rylands Library XVL (1963), pp. 423-438. 
RIVERA GARRETAS, María-Milagros - “Christine de Pizan: La utopía de un espacio separado". in RIVERA GARRETAS, María-Milagros - Textos y espacios de mujeres (Europa, siglos IV-XV). Barcelona: Karia, 1999, pp. 179-207.

SALA VILLAVERDE, Alicia, - Cristina de Pizan, una innovadora en el mundo medieval. España: Universidad Nacional de Educación a Distancia, 2015. Tese de Doutoramento.

SOUSA, Sara Rodrigues de - "Christine de Pizan em português". in LOPEZ CASTRO, Armando; CUESTA TORRE, María Luzdivina (Eds.) - Actas del XI Congreso Internacional de la Asociación Hispánica de Literatura Medieval (Universidad de León, 20al 24 de septiembre de 2005). Vol. II. León: Servicio de Imprenta de la Universidad de León, 2007, pp. 967-977.

WILLARD, Charity Cannon - “A Portuguese Translation of Christine de Pisan's Livre des Trois Vertus". PMLA 78, 5 (1963), pp. 459-464.

WILLARD, Charity Cannon - "The Manuscript Tradition of the Livre Des Trois Vertus and Christine de Pizan's Audience". Journal of the History of Ideas 27, 3 (1966), pp. 433-444.

\section{NOTAS}

1. LOIS, Élida - "La crítica genética: un marco teórico sobre la disciplina, objetivos y método". Creneida [Em linha] 2 (2014), pp. 57-78 [Consultado a 10 de Julho de 2017]. Disponível em www.creneida.com/revista/creneida-2-2014/la-cr\%C3\%ADtica-gen\%C3\%A9tica-un-marco-te\% C3\%B3rico-sobre-la-disciplina-objetivos-y-m\%C3\%A9todos-\%C3\%A9lida-lois/, p. 76.

2. LOIS, Élida - "La crítica genética”, pp. 76-77.

3. BRANDENBERGER, Tobias - "Una traducción bajomedieval y su público: notas acerca del Espelho de Cristina (Lisboa, 1518)”. in MARTÍNEZ ROMERO, Tomàs; RECIO, Roxana (Eds.) - Essays on Medieval Translation in the Iberian Peninsula. Castelló de la Plana: Publicacions de la Universitat Jaume I, 2001, pp. 75-94, p. 75.

4. PIZAN, Christine de - O Livro das Tres Vertudes a Insinança das Damas. Ed. e Introdução de Maria de Lourdes Crispim. Lisboa: Editorial Caminho, 2002, pp. 31-37.

5. Abordarei esta questão na p. 11 e seguintes.

6. BRANDENBERGER, Tobias - "Una traducción", p. 75.

7. LEAL, Ivone - Cristina de Pisano e todo o universo de mulheres. Colecção Cadernos da condição feminina 52. Lisboa: Comissão para a igualdade e para os direitos das mulheres, 1999, p. 9.

8. "Cristina es una presencia fuerte en todos sus escritos. Los autores pueden escribir en primera o en tercera persona, en este último caso, tomando cierta distancia - aunque sea sólo convencionalmente - de la acción. Ella usa la primera persona e interviene reiteradamente con el famoso moi, Christine para asegurarse de que todos sepan - sepamos - que es su opinión y su experiencia la que anota, o bien indicando, a propósito de algún episodio especialmente significativo, que lo vimos con nuestros propios ojos". HOMET, Raquel - "Espacios femeninos en la pluma de Christine de Pizan. El Libro de las tres virtudes o Tesoro de la Ciudad de las Damas". Comunicação apresentada no IV Congreso Internacional de Estudios Medievales - VI Encuentro de Estudios Medievales, San Juan, Argentina, 2015, pp. 3-4. Disponível em: www.academia.edu/28949169/ESPACIOS_FEMENINOS_EN_LA_PLUMA_DE_CHRI STINE_DE_PIZAN 9. É de notar que o nome da mãe de Christine não é conhecido.

10. María-Milagros Rivera Garretas refere que a autora tinha três anos na altura da mudança, enquanto Marie-José Lemarchand indica que Christine “[a]penas tendría cuatro años" aquando da sua chegada a França. Por sua vez, Eliana Carrara, que vai reconstruindo o percurso de vida da escritora resgatando as passagens autobiográficas da 
sua obra, não estabelece a idade com que emigrou, mas cita documentos que provam que Tommaso de Pizzano teria estado em Veneza pelo menos até Setembro de 1364 e, ainda, uma passagem em que Christine afirma que, antes de ela e a sua família terem viajado para se reunirem com o seu pai, este estaria a morar na corte francesa há cerca de três anos. Cf. RIVERA GARRETAS, María-Milagros - "Christine de Pizan: La utopía de un espacio separado". in RIVERA GARRETAS, María-Milagros - Textos y espacios de mujeres (Europa, siglos IV-XV). Barcelona: Karia, 1999, p. 182; PISAN, Christine - La Ciudad de las Damas. Ed., tradução e introdução de Marie-José Lemarchand. $2^{\mathrm{a}}$ ed. Madrid: Ediciones Siruela, 2001, p. 11 e CARRARA, Eliana - "Christine de Pizan. Biografia di una donna di lettere del XV secolo". Quaderni medievali 29 (1990), p. 67.

11. PISAN, Christine - La Ciudad de las Damas. Ed. Marie-José Lemarchand, p.11.

12. RIVERA GARRETAS, María-Milagros - "Christine de Pizan”, p. 184.

13. CARRARA, Eliana - "Christine de Pizan", p. 77.

14. PISAN, Christine - La Ciudad de las Damas. Ed. Marie-José Lemarchand, p. 56.

15. Os dados para realizar esta breve resenha biográfica foram colhidos nos textos supracitados de Eliana Carrara, Marie-José Lemarchand e Maria-Milagros Rivera Garretas e, ainda, na Tese de Doutoramento de A. Sala Villaverde - Cristine de Pizan, una innovadora en el mundo medieval. España: Universidad Nacional de Educación a Distancia, 2015. Apenas refiro em nota as informações que constam em apenas um daqueles textos ou que, dada a sua relevância, mereceram uma menção individual. As restantes podem sem encontradas nos autores indicados.

16. SALA VILLAVERDE, Alicia - Cristina de Pizan, una innovadora en el mundo medieval. España: Universidad Nacional de Educación a Distancia, 2015. Tese de Doutoramento.

17. HANLEY, Sarah - "La ley sálica”. in FAURÉ, Christine (Dir.) - Enciclopedia histórica y política de las mujeres. Europa y América. Trad. Marisa Pérez Colina. Madrid: Akal, 2010, p. 25.

18. HANLEY, Sarah - "La ley sálica”, p. 26.

19. AGOSTINHO, Paulo Jorge; MARTINS, Miguel Gomes; MONTEIRO, João Gouveia - Guerra e Poder na Europa Medieval. Das cruzadas à guerra dos 100 anos. Coimbra: Imprensa da Universidade de Coimbra, 2015, pp. 343-345.

20. SALA VILLAVERDE, Alicia - Cristine de Pisan.

21. AGOSTINHO, Paulo Jorge et al. - Guerra e Poder na Europa Medieval, p. 276.

22. SALA VILLAVERDE, Alicia - Cristine de Pisan, p. 32.

23. WILLARD, Charity Cannon - "The Manuscript Tradition of the Livre Des Trois Vertus and Christine de Pizan's Audience". Journal of the History of Ideas 27, 3 (1966), pp. 433-444.

24. WILLARD, Charity Cannon - "The Manuscript", p. 436.

25. Treze anos depois de ter escrito este artigo, aquando da redacção da introdução e das notas da edição crítica do Livre des trois vertus, publicada em 1989 com Eric Hicks, C. C. Willard refere a existência de vinte e um manuscritos. Manteve, no entanto, o número dos pertencentes ao primeiro grupo (apenas um) e o dos que tiveram como suporte o papel (nove). Cito de acordo com LACARRA LANZ, Eukene - "Las enseñanzas de Le livre des trois vertus à l'enseignement des dames de Christine de Pizan y sus primeras lectoras". Cultura Neolatina LXI (2001), p. 27. Contudo, as conclusões a que chega esta autora diferem em grande medida das de C. C. Willard, na medida em que afirma que os manuscritos acima referidos seriam "manuscritos lujosos, la mayor parte de cuyos propietarios o propietarias pertenecían a la realeza y a la más alta nobleza". A autora fundamenta esta afirmação no trabalho de Sandra L. Hindman (Christine de Pizan's "Epistre Othéa". Painting and Politics at the Court of Charles VI, de 1986) e, ainda, no de June MacCash ("The cultural patronage os medieval women", de 1996). Tendo sido possível verificar apenas o segundo, verifica-se que June MacCash cita C. C. Willard e os dezoito manuscritos listados no seu artigo de 1966, sem todavia chegar à conclusão de Eukene Lacarra. Por sua vez, Tobias Brandenberger, no artigo "Una traducción", e com base nos mesmos trabalhos de C. C. Willard (o de 1966 e e de 1989) 
citados por Eukene Lacarra, indica uma vintena de manuscritos e afirma "[f]altan copias de lujo (que sí que existen en el caso de otras obras de Christine que gozaron de gran aprecio en las familias de la alta aristocracia), pero existen varios manuscritos de papel cuyas características obligan a pensar en lectores (o lectoras) de clase media" (pp. 83-84). A uma conclusão similar chega Rosalind Brown-Grant, que indica "the Trois Vertus seems to have appealed more to a middle-class audience at the end of the fifteenth century than to Christine's immediate patrons, the royal families of Orléans, Burgundy and Berry, since no luxurious presentation copy of the text survives, whereas there is an unusually high number of paper manuscripts which were presumably owned by a less wealthy readership" (Christine de Pizan and the moral defence of women. Reading beyond gender. Cambridge: Cambridge University Press, 1999, p. 176). Feitas as contas, se dos dezoito manuscritos referidos em 1966 nove seriam em papel, um pertencia ao primeiro grupo, dois ou três ao segundo, e cinco ou seis ao terceiro. O aparecimento de mais três manuscritos que não se inserem nem no primeiro, nem no quarto grupo não consegue instaurar um desiquilíbrio suficientemente forte para revogar as primeiras conclusões de C. C. Willard, ou seja, o facto de $40 \%$ dos vinte e um manuscritos que chegaram até nós serem em papel, apesar da fragilidade do suporte quando comparado com o pergaminho, e da incúria das Bibliotecas que os possuíam (que não as aristrocráticas). Posto isto, continua a ser inegável a circulação deste texto em ambiente não cortesão. Assim sendo, serão referidos apenas os dezoito manuscritos indicados no artigo de C. C. Willard de 1966, mantendo a distribuição dos manuscritos pelos diversos grupos e a leitura que faz do respectivo significado.

26. PICKFORD, Cedric E. - "Fiction and the reading public in the fifteenth Century". Bulletin of the John Rylands Library XVL (1963), p. 435.

27. HOMET, Raquel - “Espacios femeninos", p. 2.

28. LEAL, Ivone - Cristina de Pisano, p. 7.

29. LEAL, Ivone - Cristina de Pisano, p. 18.

30. LACARRA LANZ, Eukene - "Las enseñanzas", p. 28.

31. LEAL, Ivone - Cristina de Pisano, pp. 18-19.

32. MENDONÇA, Manuela - “O Espelho de Cristina (séc. XV)". in História Revista 18, 1 (2013), p. 54.

33. MENDONÇA, Manuela - "O Espelho de Cristina (séc. XV)”, pp. 54-57; LACARRA LANZ, Eukene "Las enseñanzas", pp. 33-34; PIZAN, Christine de - O Livro das Tres Vertudes. Ed. Maria de Lourdes Crispim, p. 30, entre outros.

34. MENDONÇA, Manuela - "O Espelho de Cristina (séc. XV)", p. 62.

35. BUESCU, Ana Isabel - "Educar o Príncipe no Século XVI". in BUESCU, Ana Isabel - Na corte dos Reis de Portugal. Saberes, ritos e memórias. $2^{\text {a }}$ Ed. Lisboa: Edições Colibri, 2011, p. 39.

36. BUESCU, Ana Isabel - "Educar o Príncipe", pp. 37-41.

37. RIVERA GARRETAS, María-Milagros - "Christine de Pizan”, p. 189.

38. PIZAN, Christine de - $O$ Livro das Tres Vertudes. Ed. Maria de Lourdes Crispim, pp. 32-34.

39. São múltiplas as fontes onde se pode verificar esta informação. Em particular, e dado o teor do presente trabalho, faço menção aos artigos de WILLARD, Charity Cannon - "A Portuguese Translation of Christine de Pisan's Livre des Trois Vertus". PMLA 78, 5 (1963), pp. 459-464; MENDONÇA, Manuela - "O Espelho de Cristina"; e, ainda, CORREIA, Licínia Maria da Trindade - A Insinança das Damas. Formas de Poder Feminino no século XV (o caso de Isabel de Lencastre). Lisboa: Universidade Nova de Lisboa, 2013. Dissertação de Mestrado, entre outros.

40. Segundo alguns autores, Isabel de Borgonha, na época em causa, ainda não dominava bem o francês, o que justificaria a necessidade de realizar a tradução antes do seu casamento, ou nos seus primeiros tempos na corte borguinhona. Veja-se PIZAN, Christine de - O Livro das Tres Vertudes. Ed. Maria de Lourdes Crispim, p. 33. 
41. "[...] o qual liuro foy tornado de ffrançes em esta nossa linguaJem portugues per mandado da muyto exçillente $e$ conprida de muytas vertudes Senhora a Rainha dona Jsabel molher do muyto alto $e$ muyto exçilente prinçepe e Senhor El Rey dom afonso o quynto de portugal $e$ do algarue $e$ Se nhor de çepta". PISAN, Christine de - Livro das tres vertudes, Ms. mss/11515, f. 1r..

42. Segundo os dados paleográficos, o manuscrito é posterior a 1440 e, muito provavelmente, posterior a 1450, o que vai ao encontro do que se pode inferir do incipit do códice. Com efeito, sabemos que Isabel de Coimbra foi rainha consorte de 1447 a 1455 e que a fórmula da intitulação de D. Afonso V entre 1446 e 1458 era "Dom Afonso pela graça de Deus Rei de Portugal e dos Algarves e senhor de Ceuta", balizas temporais que coincidem com as obtidas dos dados exclusivamente paleográficos.

43. PIZAN, Christine de - O Livro das Tres Vertudes. Ed. Maria de Lourdes Crispim, p. 34.

44. PIZAN, Christine de - O Livro das Tres Vertudes. Ed. Maria de Lourdes Crispim, p. 30.

45. PIZAN, Christine de - O Livro das Tres Vertudes. Ed. Maria de Lourdes Crispim, p. 35.

46. Cf. LEAL, Ivone - Cristina de Pisano, pp. 16-17.

47. Neste contexto, o termo a utilizar seria exemplar e não testemunho (não são termos equivalentes).

48. SOUSA, Sara Rodrigues de - "Christine de Pizan em português". in LOPEZ CASTRO, Armando; CUESTA TORRE, María Luzdivina (Eds.) - Actas del XI Congreso Internacional de la Asociación Hispánica de Literatura Medieval (Universidad de León, $20 a l 24$ de septiembre de 2005). Vol. II. León: Servicio de Imprenta de la Universidad de León, 2007, p. 967.

49. LEAL, Ivone - Cristina de Pisano, p. 19.

50. LEAL, Ivone - Cristina de Pisano, p. 26, nota 16.

51. LEAL, Ivone - Cristina de Pisano, p. 19.

52. Tobias Branderberger refere-se (em ambos os artigos aqui citados) a este manuscrito, hoje perdido, como "o original francês". Sendo o conceito de original complexo e discutível, usarei o termo antecedente.

53. BRANDENBERGER, Tobias - "Una traducción”, pp. 77-78.

54. BRANDENBERGER, Tobias - "Christine de Pizan em Portugal: as traduções do Livre des Trois Vertus". in EARLE, Tom F. (Ed.) - Actas do Quinto Congresso da Associaçào Internacional de Lusitanistas. Universidade de Oxford: 1 a 8 de Setembro de 1996. Vol. I. Oxford / Coimbra: Associação Internacional de Lusitanistas, 1998, p. 426.

55. Este fenómeno não obedece apenas à importância dada às diversas camadas sociais ou ao conhecimento mais ou menos aprofundado que Christine teria de cada uma de elas, mas, ainda, ao facto de a autora tratar logo na primeira parte de questões que diziam respeito a todas as mulheres e às quais, feita a aclaração pertinente, não voltará nas seguintes secções do livro.

56. BRANDENBERGER, Tobias - “Christine de Pizan em Portugal”, pp. 430-431.

57. BRANDENBERGER, Tobias - "Una traducción”, pp. 78-80.

58. Isto evidencia-se ainda noutros pormenores da tradução que, pelas características deste trabalho, não foram aqui abordados. Veja-se BRANDENBERGER, Tobias - "Christine de Pizan em Portugal", pp. 431-432.

59. BRANDENBERGER, Tobias - "Christine de Pizan em Portugal", p. 427.

60. BRANDENBERGER, Tobias - "Christine de Pizan em Portugal", p. 428.

61. No seu artigo "Una traducción", Tobias Brandenberger aborda ainda a questão do género do receptor no momento tanto de redigir uma obra, como de realizar a sua tradução. Dadas as características do presente trabalho, apenas referirei que, no que diz respeito a esta questão, a tradução respeita o que o autor denomina configuração do gender da obra, pois mantém a escrita anti-misógina e amplia o enfoque didáctico aos homens na segunda e terceira parte, tal como Christine fez (veja-se pp. 84-91). 


\section{RESUMOS}

Em 1405, Christine de Pisan redigiu um tratado didáctico de grande sucesso na época: o Livre des Trois Vertus. Posteriormente, entre 1428 e 1455, o texto foi traduzido para português e, em 1518, a obra foi impressa em Lisboa por ordem de D. Leonor, com o título Espelho de Cristina. O presente artigo recolhe, de forma sucinta, as particularidades dos contextos social, histórico e político tanto da França de inícios do século XV - onde nasce a obra - como de Portugal na altura da sua tradução e posterior impressão, assim como as características e o laço existente entre as cortes de ambos os países. Tentar-se-á ainda identificar qual era o público-alvo previsto em cada caso, com o intuito de encontrar um elo de ligação entre estes elementos e as alterações que o texto sofreu no decorrer da sua transmissão.

In 1405, Christine de Pisan wrote a book of instruction that reached great success at the time: the Livre des Trois Vertus. Later, between 1428-1455, the text was translated into Portuguese and, in 1518, queen D. Leonor ordered its printing in Lisbon with the title Espelho de Cristina. The present article briefly summarizes the particularities of the social, historical and political contexts of France from the beginning of the fifteenth century - where the work is born - and of Portugal at the time of its translation and subsequent printing, as well as the characteristics and the ties between the courts of both countries. It also aims to identify the target audience foreseen in each case, in order to find a link between these elements and the changes that the text suffered in the course of its transmission.

\section{ÍNDICE}

Keywords: Christine de Pisan, Livre des trois vertus, Espelho de Cristina, medieval translation, textual transmission

Palavras-chave: Christine de Pisan, Livre des trois vertus, Espelho de Cristina, tradução medieval, transmissão textual

\section{AUTOR}

\section{ANA LUISA SONSINO}

Centro de Linguística da Universidade de Lisboa, Faculdade de Letras da Universidade de Lisboa, 1600-214, Lisboa, Portugal

asonsino@campus.ul.pt

https://orcid.org/0000-0001-7718-6737 